\title{
Crop-livestock diversification in the mixed farming systems: implication on food security in Northern Ghana
}

\author{
Gideon Danso-Abbeam ${ }^{1,2}$, Gilbert Dagunga ${ }^{3^{*}}$ (D) Dennis Sedem Ehiakpor ${ }^{1}$, Abiodun A. Ogundeji ${ }^{2}$, \\ Edinam Dope Setsoafia ${ }^{1}$ and Joseph A. Awuni ${ }^{4}$
}

\begin{abstract}
Background: Achieving food security is a global priority and a concern for most African countries, including Ghana. Food systems providing varied and healthy diets without compromising the natural resource base, such as integrated crop-livestock diversification, are important for development planning and policy. Using cross-sectional data obtained from 1284 smallholder households in northern Ghana, we used a double-censored Tobit model in a conditional mixed-process (CMP) framework to estimate the impact of crop diversification on household food security.

Results: The results showed that household-specific, socioeconomic, and institutional factors influence crop-livestock diversification and food security in northern Ghana. Moreover, we found that higher intensity of crop-livestock diversification translates into a greater probability of achieving food security.

Conclusions: Crop-livestock diversification is essential to Ghana's pursuit of the zero-hunger global agenda as it enhances food security without adversely affecting biodiversity and ecosystem health. Therefore, it should be incorporated into Ghana's ongoing agricultural programme dubbed, planting and rearing for food and jobs.
\end{abstract}

Keywords: Household dietary diversity score, Margalef index, Conditional mixed process, Northern Ghana

\section{Background}

The second Sustainable Development Goal (SDG 2) is to eliminate hunger, achieve food security, improve nutrition, and promote sustainable agriculture. It is widely acknowledged that meeting these targets will necessitate all nations maintaining sustainable food production systems by 2030, as well as promoting efficient agricultural practices that improve productivity and production. As highlighted in the fourth SDG goal, such a production system can sustain biodiversity while also improving climate change adaptation capacity, gradually increasing land and soil quality [52]. As a result, an urgent call

\footnotetext{
*Correspondence: dagungagilbert@gmail.com

${ }^{3}$ Science Department, St. John Bosco's College of Education, Navrongo, Ghana
}

Full list of author information is available at the end of the article to improve food production through conservative agricultural practices that do not jeopardize environmental quality or degrade land becomes necessary. It is especially important for most agrarian economies, such as Ghana, because agriculture employs the majority of the workforce. According to Statista [48], agriculture provides a living for approximately $33.5 \%$ of Ghana's population. This emphasizes the importance of preserving the natural base from which the populace's livelihood is derived.

Mixed farming has been proposed as one of the most important means of achieving food security without endangering the environment [27, 39]. Mixed farming is a farming method in which farmers grow crops and raise livestock on the same piece of land. Mixed agriculture, according to Mekuria and Mekonnen [39], is the simultaneous process by which farmers grow crops and rear farm animals to maintain sustainable agriculture. 
In a mixed farming system, livestock manure is used to fertilize crop farmlands while the animals provide traction for farming. Several empirical studies have concluded that mixed farming is the most important farming system for developing economies, particularly in Sub-Saharan Africa (SSA), home to over 166 million agro-pastoralists [27]. Mixed farming also allows farmers to diversify their resources to balance crop and animal production.

Crop-livestock diversification refers to the process of increasing the variety and scale of production of these crops and livestock within the framework of a mixed farming system. Crop-livestock diversification is thus the production of different $\operatorname{crop}(\mathrm{s})$ and livestock(s) on available land space [39]. Agricultural intensification is recommended for most African economies as the best structural agricultural growth path. It includes integrated crop-livestock diversification, which incorporates complementary benefits and productivity [17, 42]. Crop-livestock diversification is viewed as a deliberate mechanism by which households in developing economies such as Ghana can combat poverty and achieve food security [8,22]. According to Asante et al. [8], crop-livestock production systems provide more than half of the global food supply while also helping to reduce production costs due to economies of scope. According to Murendo et al. [41], agricultural intensification mechanisms such as crop-livestock diversification are an important tool in achieving food and nutrition security in developing economies. These intensification mechanisms are essential in light of rising population growth, which puts strain on agricultural land and limits the potential for exponential agricultural intensification. However, intensive farming and continuous cultivation without conservation practices will deplete soil nutrients [39]. Various studies have examined these distinct concepts of farm diversification, particularly crop diversification, in order to suggest efficient combinations of farm practices [24]. However, Liyama et al. [27] advocated for more diverse interactions between crop and livestock components in the intensification process. Makinde et al. [35] emphasized that the optimal use of livestock manure in a mixed farming system might provide poor agriculturalpastoralists with long-term harvest intensification, especially since they cannot afford expensive inorganic fertilizers. Intensifying crop-livestock diversification is also a method of conserving biodiversity, improving dietary preferences, and reducing farm households' vulnerability to shocks [39]. According to Waha et al. [54], crop-livestock farming systems play an important role in ensuring household food security in sub-Saharan Africa.
According to FAO [22] p. 8, "food security exists when all people have physical, social, and economic access to adequate, safe, and nutritious food that meets their dietary needs and food preferences for an active and healthy life at all times." The availability of enough, healthy, and nutritious food to sustainably support household members at all times is referred to as household food security $[5,43]$. To achieve food security, households must always have access to sufficient and well-balanced food supplies. Thus, despite the multifaceted nature of food security, one critical dimension is household access to an adequate amount of food on a sustainable basis [10]. Households have access to food when they have the means to purchase the appropriate quantity and quality of food to meet their dietary and nutritional needs [14]. The literature on household food security $[5,9,10,14,43$, 56] suggests that food insecurity persists if households are unable to provide enough food for all members to live a healthy and active lifestyle. In 2017, approximately 770 million people, or nearly $10 \%$ of the world's population, were at risk of severe food insecurity. Regional values range from $1.4 \%$ in North America and Europe to nearly $30 \%$ in Africa [25]. According to these statistics, the majority of the world's food insecure people live in Africa, which is a very concerning situation.

Agriculture is inextricably linked to food and nutrition security because the sector produces food for human consumption. Murendo et al. [41] proposed that farming systems such as integrated crop-livestock production influence household nutrition through food production or animal production, which affects household food intake, agricultural product sales, and, ultimately, food purchasing and consumption. Despite the enormous potential benefits of integrated crop-livestock diversification in developing countries, empirical literature on crop-livestock diversification in sub-Saharan Africa, particularly Ghana, is scarce. This study contributes to the literature in the following ways. First, most studies [42] (e.g. [2, 12]) on household diversification focus on income diversification, livelihood, and non-farm employment. One of the shortcomings of measuring income or livelihood diversification is that it does not adequately highlight the interactive potential of crop-livestock diversification. Using the Margalef index, this study addresses this gap by assessing how farm households diversify both crop and livestock at the same time. Unlike other indices (e.g., Simpson, Herfindahl, and Ogive) used to assess household diversification, the Margalef index has a strong distinguishing capacity, improved goodness of fit, and can capture various crop and animal species [24]. Second, we use conditional mixed-process (CMP) to assess the impact of crop-livestock diversification on household food security while accounting for sample 
selection bias caused by both observed and unobserved heterogeneity. Third, crop-livestock diversification is assumed to be potentially endogenous. Failure to account for this can lead to an underestimation or overestimation of the true impact of crop-livestock diversification on food security. Finally, northern Ghana is regarded as the poorest region of the country, with severe food insecurity compared to the southern region [43]. Given the enormous importance of crop-livestock diversification in food security, the environment, and biodiversity, it is critical to investigate its role in the mixed farming system in household food security.

\section{Concepts and measurements of food security}

Food security has been the main priority of many nations, particularly developing countries, to issue of hunger and poverty. Food security, as outlined above, comprises four fundamental dimensions: availability, accessibility, utilization, and stability. At the household level, adequate food should be available to feed the members, either through personal production or through local markets [21]. In some areas, food assistance can supplement food availability during an emergency. Food and gifts made from wild foods can also aid with food access. Households have access to food if they have the means to purchase the appropriate quantities and quality to meet their nutritional and dietary needs $[4,21]$. It denotes a household's ability to secure food through household income or external sources such as transfers or contributions. This emphasizes the significance of household purchasing power. It is determined by elements such as household income, food costs, employment opportunities, and working resources such as labor, capital, and capacity. The notion of food utilization relates to the human body's ability to absorb safe and nutritious meals required for a healthy diet $[21,33]$. It is determined by the amount, quality, and variety of food consumed in homes, and adequate health care, sanitation, and maternal and child care. Food utilization also includes family food management, which provides for appropriate practices in food processing, storage, preparation, nutrition, and equitable intra-household food distribution [16]. Stability is typically related to vulnerabilities and risk factors that may negatively impact food availability or access [21, 31]. It requires that people and households have food at all times to always have access to the nutrition they require.

Food insecurity, on the other hand, arises when households, members of a community, or a country does not have constant access to high-quality, safe food to meet their daily energy demands [22]. FAO [23] redefined food and nutrition insecurity as "a situation that exists when people lack secure access to sufficient amounts of safe and nutritious food for normal growth and development and an active and healthy life. It may be caused by the unavailability of foods, insufficient purchasing power, inappropriate distribution, or inadequate use of food at the household level. Food insecurity, poor conditions of health and sanitation, and inappropriate care and feeding practices are the major causes of poor nutritional status". Thus, households become food insecure when they do not demonstrate resilience to food availability, access, and utilization. Food insecurity is defined as a household's consistent failure to provide nutritional, safe, and culturally acceptable food for all of its members [1]. In general, food insecurity occurs in two time dimensions: acute and chronic food insecurity. A shock, such as a flood, storm, or drought, unanticipated food price increases, conflicts, or other incidents that cause instability and disrupt the regular survival of impacted households, leads to acute food insecurity. Chronic or long-term food insecurity, on the other hand, is frequently the result of poverty. A lack of food availability can cause chronic food insecurity Chronic food due to low-income production and market failures.

At the moment, there is no global standard methodology for measuring food security status at the household, community, regional, or even national levels $[18,29,30$, 31]. In general, household food security indicators are divided into three categories: dietary recall, psychological and physical experience, and coping mechanisms [26]. Food security dietary recall measurements include the Household Dietary Diversity Score (HDDS) and Food Consumption Scores (FCS). The dietary diversity score is a snapshot technique that shows the household's ability to consume a variety of food kinds, whereas the FCS measures both the diversity and frequency of food consumption [18, 22]. Food security metrics such as the Household Hunger Scale (HHS), Food Insecurity Experience Scale (FIES), and Household Food Insecurity Access Scale (HFIAS) are psychological and physical experiences based on households' perceptions of food deprivation $[10,14]$. FIES, for example, assesses the severity of latent food insecurity, which is usually defined as the inability to obtain free access to the food required to live a healthy, active, and dignified life [10]. In terms of coping strategies, the coping strategy index (CSI) is designed to examine what households do when they do not have enough food. The CSI tracks the regularity with which families adopt various coping techniques over time, assessing a household's level of "food insecurity" based on the frequency and severity of these behaviors [18]. Santeramo [45] offers a road map for building a composite index for measuring food security due to heterogeneity among 
food security indicators and the lack of consensus on how to compare food security status among countries. ${ }^{1}$

The majority of these indicators focus on a specific aspect of food security, and the conclusions drawn from their use are limited to their limitations. As a result, no single indicator captures all aspects of food security [38]. The Household Food Insecurity Access Scale (HFIAS) assesses both the prevalence and frequency of food insecurity in households. It represents the universal dimensions related to food insecurity access [34]. The World Food Programme's Household Food Consumption Score (HFCS) prioritizes quality. Dietary diversity has long been regarded as an important component of both diet quality and diet quantity, as eating a variety of foods helps ensure adequate intakes of critical nutrients and promotes overall health [46]. As a result, the Household Dietary Diversity Score (HDDS) was used in this study's research to determine food security.

\section{Empirical evidence on food security in Ghana}

Food security is a global concern addressed in the 2030 Sustainable Development Goals. In 2016, it was estimated that 815 million people worldwide were food insecure [50]. Between 2000 and 2015, approximately 900 and 777 million people were food insecure, with incidence rates of 14.9 and $10.9 \%$, respectively $[24,25]$. In addition, food insecurity was expected to affect 203.6 million and 220 million people in Sub-Saharan Africa in 2000 and 2015, with a prevalence of 30 and $23.2 \%$, respectively [24].

In Ghana, food crop output during and between cropping seasons is virtually entirely dependent on rainfall. This has resulted in some food insecurity among households and communities. However, the country is largely food secure [15]. The Ghana Ministry of Food and Agriculture (MoFA) [40] defined food security in Ghana as "good quality nutritious food hygienically packaged, esthetically presented, available in sufficient quantities all year round, and located at the correct place at accessible rates." According to the 2017 Global Food Security Ranking, Ghana is one of the most food-secure countries in Sub-Saharan Africa (South Africa and Botswana are the only countries ahead of Ghana) [53]. According to MoFA [40], about $5 \%$ of Ghana's population (1.2 million people) is food insecure. The World Food Program (2009) estimated in 2009 that approximately 34\%, 15\% and $10 \%$ of the population in the Upper West, Upper East and Northern regions of Ghana experienced food insecurity. Furthermore, according to Food Security and Nutrition Monitoring Systems [FSNMS] of WFP [55],

\footnotetext{
${ }^{1}$ Although the recommendation for having a composite indicator suggested by Santeramo [45] looks fantastic, the data for this study are insufficient to support the building of such a composite food security index.
}

Ghanaians are generally food secure, with $91.5 \%, 7.7 \%$, and $0.8 \%$ being food secure, moderately food insecure, and severely food insecure, respectively. Nkegbe et al. [43], on the other hand, used the HHS to assess the state of food security in northern Ghana and concluded that food security remains unacceptably low in modern society. According to Darfour and Rosentrator [10], approximately $5 \%$ of Ghana's population is food insecure, with an additional 2 million at risk of becoming so. Tuholske et al. [51] conducted a comparable study in nine low and middle-income areas of Accra, Ghana, and found that the majority $(70 \%)$ of households were classified as mildly to severely food insecure when measured using the Household Food Insecurity Access Prevalence Index (HFIAP). However, approximately $2.1 \%$ of the sampled households were classified as food insecure when assessed with FCS.

Despite significant policy initiatives and programs implemented by successive governments to address the situation, evidence of food poverty persists in many northern Ghanaian communities. The Food and Agricultural Sustainable Development Plans I and II, and the ongoing Planting for Food and Jobs (PFJ) initiative, all aim to boost local output by subsidizing farm inputs and providing improved seeds and agricultural extension services. However, more needs to be done to get the country out of food insecurity, especially in the north [53].

\section{Materials and methods \\ Data source and study area}

The study uses secondary data obtained from the International Food Policy Research Institute (IFPRI) under the Ghana Africa Research in Sustainable Intensification for the Next Generation (Africa RISING) 2015 baseline survey. The data were collected from 1284 households across the three northern regions (i.e., 222 households from the Upper East, 447 from the Upper West and 615 from the Northern regions). The data from the Upper East region were collected from the Bongo, Kassena-Nankana east, and Talensi-Nabdam districts. That from the Upper West region was collected from Wa west, Wa east, and Nandowli districts, while data from the Northern region were taken from the Tolon/Kumbungu, Savelugu, and West Mamprusi districts. Northern Ghana accounts for about half of the total land surface of Ghana, but the least developed. Northern Ghana has a relatively dry climate, with a single rainy season that lasts from May to October. The average rainfall intensity ranges between 750 and $1050 \mathrm{~mm}$. The dry season begins in November and ends in March/April, with high temperatures in December and January at the peak of the dry season (March-April). Agriculture is the mainstay of the majority and most of the households engage in crops such as cereals, legumes, roots and tubers with economic trees like dawadawa, 


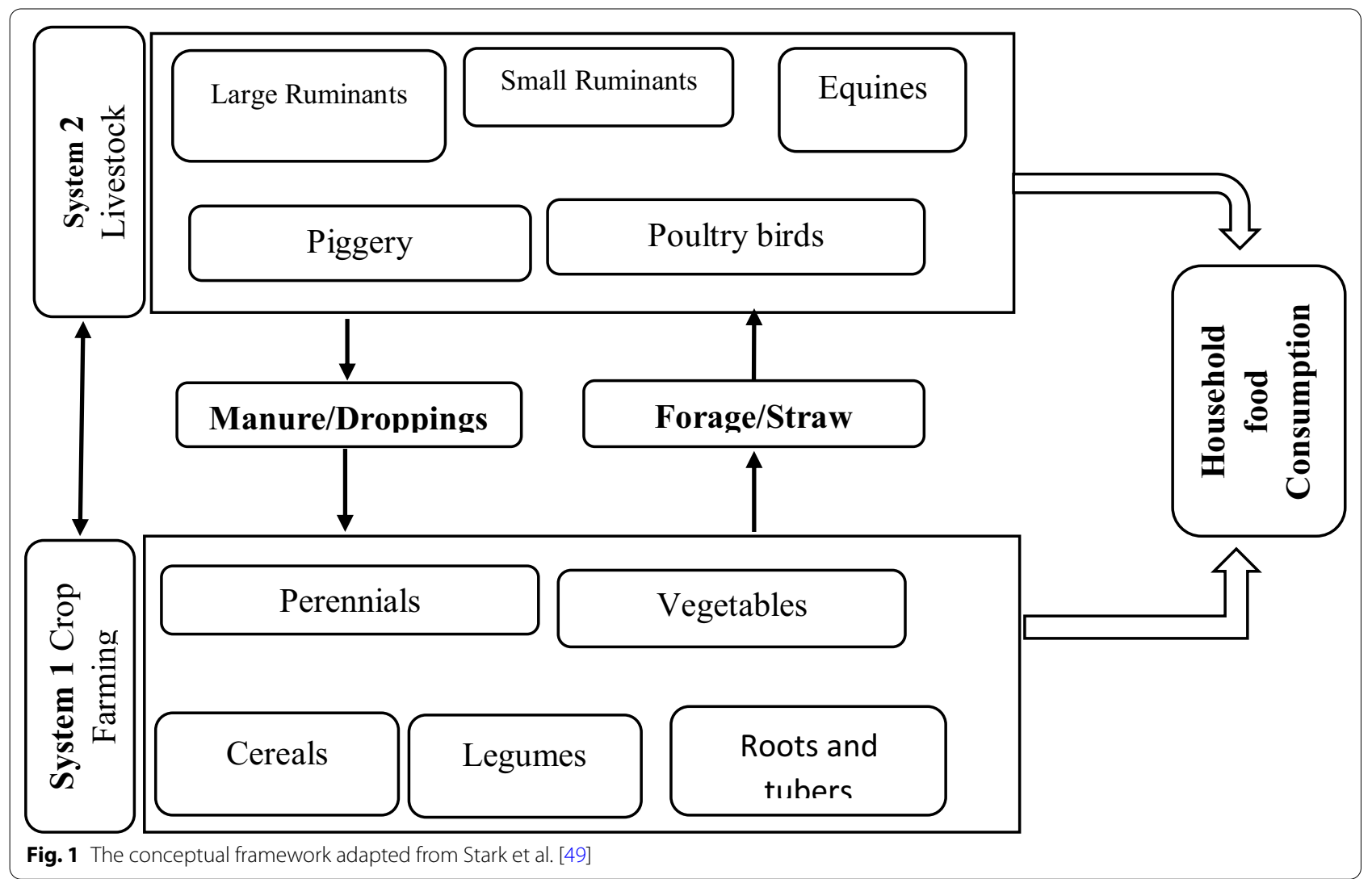

shea and cashew. Some rear livestock and poultry, while others engage in fishing, especially those around the Volta basin.

\section{Conceptual framework}

The study's conceptual framework is derived from the two-compartment network model developed by Stark et al. [49] in order to examine the input and output flows within an integrated crop-livestock system in LatinoCaribbean farms. However, in this study, the framework has been modified to show the two-way interaction between the two farming systems (i.e., crop farming or system 1 and livestock farming or system 2). System 1 is a crop farming system that includes a variety of crops such as cereals, legumes, roots and tubers, vegetables, and perennial crops. System 2 is a livestock system comprising large and small ruminants, equines, piggery, and poultry birds. These two systems are integrated within the same farmland. Their interactions are expected to increase productivity and quality within the systems, leading to increased household food consumption and, subsequently enhancing food security. Figure 1 describes the two farming systems.

\section{Analytical method and estimation technique}

This section outlines the methodology used to determine whether intensifying crop-livestock diversification improves household food security. We begin by measuring the intensity of crop-livestock diversification using the Margalef index, and then we construct household food security using the household dietary diversity score (HDDS). Finally, the conditional mixed-process method for quantifying the food security impacts of crop-livestock diversification is discussed.

\section{The Margalef index}

The study extends the conceptual framework by using the Margalef index to create diversification indices for crops (system 1), livestock (system 2), and the integrated croplivestock diversification index, which includes both crop and livestock systems. The Margalef index was chosen because it discriminates well and fits well in comparison to other diversity indices [24]. It also captures various crop and animal species units [45]. The Margalef index is given as:

$$
D_{i}=\frac{S_{i}-1}{\operatorname{In}\left(N_{i}\right)},
$$


Table 1 Margalef index by dimension, diversity portfolios and units. Source: modified from FAO [24]

\begin{tabular}{lll}
\hline Dimension & S & N \\
\hline Crop (system 1) & Number of crop types planted & Total area planted overall crop types \\
Livestock (system 2) & Number of livestock types raised & Total number of livestock over all types \\
Crop-livestock (1 and 2) & Number of crop and livestock types planted and raised & $\begin{array}{c}\text { Total number of all livestock species } \\
\text { and cropland area }\end{array}$ \\
\hline
\end{tabular}

where $D_{i}$ denotes diversification, $N_{i}$ is the total number of household-managed units of diversity options in the sample, and $S_{i}$ is the number of household-managed units of diversity for the $i$ th household. Hence, for this study, the definitions of $N_{i}$ and $S_{i}$ regarding the various systems are shown in Table 1.

A higher Margalef index value indicates greater system diversification, while a lower value indicates less system diversification (more specialization). When the Margalef index value is zero, there are very few crop species per small land or number of animals per general population [39]. These diversity indices were built using approximately 24 different crop types and 17 livestock species in this study. There were four types of cereals (maize, millet, sorghum, millet, and rice), six types of legumes (beans, soybean, pigeon pea, chickpea, groundnuts, and Bambara groundnuts), six types of vegetables (tomatoes, okra, red pepper, garden eggs, ayoyo, and watermelon), five types of roots and tubers (onions, iris potatoes, sweetpotatoes, yam and cassava and three cash crops (mango, cotton, and tobacco). The livestock, on the other hand, included five types of large ruminants (draught cattle, local bulls, improved bulls, local cows, and improved cows), four types of small ruminants (domesticated goats, exotic goats, domesticated sheep, and exotic sheep), two types of equines (horses and donkeys), two types of pigs (improved and local), and four types of poultry birds (local fowls, improved fowls, guinea fowls, and pigeons).

\section{Household Dietary Diversity Score (HDDS)}

There are various methods for measuring food security. Some measure the quantity or availability dimension of food security, while others measure the quality (nutritional aspect) of food security. For example, one of the food security measures used in studies such as Murendo et al. 41 is daily food energy consumption per capita, which only considers the quantity or availability aspect of food security, which is insufficient to represent food security. Other measures, such as the FCS, have also been criticized because they focus on the quality aspect of food security. According to Leroy et al. [34], the HDDS is a very appropriate measure for measuring food security because it considers both the availability, access, and quality or nutritional aspects of food security. Hence, it has been adopted for this study.

The HDDS for each household was calculated using 12 food groups, as recommended by FAO [17] and the INDDEX Project [28]. They include staple foods (cereals, roots and tubers), micronutrient-rich foods (vegetables, fruits, meat, eggs and fish, legumes, nuts and seeds, and milk), and energy-rich foods (oils and fats, sweets and sugars, spices and drinks). A household is coded 1 if it consumes a given food category within the last seven days, and 0 if it does not. The HDDS ranges from zero (0) to twelve (12), with a value of zero indicating that the household did not consume any food groups across all 12 categories and a value of twelve indicating that the household consumed all food groups. As a result, the higher the value, the better.

\section{Conditional mixed-process}

In this study, we identify the factors that influence croplivestock diversification and estimate its impact on household food security using the conditional mixed-process (CMP) framework. One of the major economic challenges in impact evaluation is the issue of endogeneity of the treatment variable (in our case, crop-livestock diversification). Consider equation (Eq. 2) with an outcome variable, HDDS, used as an indicator for food security. This could be expressed as:

$$
H D D S=\beta_{0}+\beta_{i} X_{i}+\alpha C L D I+\eta_{i}+\varepsilon_{i},
$$

where $H D D S$ denotes the household dietary diversity score, which measures food security. $X_{i}$ represents a vector of variables explaining the changes in $H D D S, \alpha$ measure the impact of crop-livestock diversification on food security, $\eta_{i}$ is the unobserved heterogeneity assumed to be uncorrelated with the explanatory variables $X_{i}$, and $\varepsilon_{i}$ is the error term.

Equation (Eq. 2) represents a simple approach to assessing the effects of CLDI on HDDS through the use of OLS estimator. However, performing this estimation using OLS assumes that CLDI is random and an exogenous variable, while it is non-random and potentially endogenous. The non-random sample selection problem originates from self-selection, in which farmers decide whether or not to engage in crop-livestock 
Table 2 Definition of variables, measurements and summary statistics

\begin{tabular}{llc}
\hline Variable & Measurement & Mean \\
\hline $\begin{array}{l}\text { Demographic factors } \\
\text { Sex of household head }\end{array}$ & Dummy (1 if male, otherwise 0) & 0.841 \\
Marital status of the household head & Dummy (1 if married, otherwise 0) & 0.946 \\
Age of household head & Years & 47.69 \\
Socioeconomic & & 0.365 \\
Farming as the primary occupation & Dummy (1 if farming, otherwise 0) & 0.225 \\
Household practices irrigation & Dummy (1 if yes, otherwise 0) & 14.56 \\
Farm size & Continuous (acres) & 0.12 \\
Land ownership & Dummy (1 if yes, otherwise 0) & 3.917 \\
Institutional factors & & 0.872 \\
Access to agricultural credit & Dummy (1 if yes, otherwise 0) & 0.096 \\
Extension service & Dummy (1 if yes, otherwise 0) & 0.189 \\
Farmer groups & Dummy (1 if yes, otherwise 0) & 0.608 \\
Non-farm employment & Dummy (1 if yes, otherwise 0) & 0.352 \\
Crop diversity index & Index & 0.037 \\
Livestock diversity index & Index & 0.333 \\
Crop-livestock diversity index & Index & 1.801 \\
\hline
\end{tabular}

diversification, most often due to disparities in resource endowment. The endogeneity comes from the fact that other factors also determine CLDI. Hence, failure to control this may result in bias estimates of the true effect of crop-livestock diversification. Many pieces of literature (Afolami et al. 2015, [19, 40, 47] have suggested that the standard approach to deal with the problem of endogeneity and self-selection bias is the Instrumental Variable (IV) technique such as CMP framework.

CMP is an empire of multi-equation structures capable of taking a different format of dependent variables. In CMP framework, the dependent variable can be any type of model like logit/probit, ordered, categorical, censored (Tobit), 2-stage squares (2sls) and Heckman model [44]; hence, the phrase "mixed-process". The CMP deals with both simultaneity and endogeneity, where consistent estimates are produced for the structural equation system in which all endogenous variables are observed on the right-hand side of the equation and unobserved selectivity biases that may arise from hidden households characteristics such as managerial skills are also accounted for [6]. In addition, the CMP is based on the seemingly unrelated regression (SUR) system, where cross-equations of error terms are associated [37].

The potential endogenous variable $C L D I$ can also be specified as:

$$
C L D I_{i}=\beta_{0}+\beta X_{i}+\varepsilon_{i},
$$

where $C L D I$ is the crop-livestock diversification index, $X$ denotes a set of variables reported in Table 2 and $e$ is the error term. The dependent variable of the outcome model in Eq. (1) ranges between 0 and 12. As mentioned earlier, the endogeneity nature of CLDI can lead to over- or under-estimation of the true effect of CLDI on food security. In order to account for this possibility, a double-censored Tobit model was employed within the framework of CMP to jointly estimate Eqs. (2) and (3) as suggested by Roodman [44].

Considering the endogeneity of the CLDI in Eq. (2), the joint marginal probability can be expressed as:

$$
\iint_{\eta_{3} \eta_{2}}\left[\prod L_{3}\left(\eta_{3}\right) \prod L_{2}\left(\eta_{2}\right)\right] f\left(\eta_{3}, \eta_{2}\right) d \eta_{3} d \eta_{2}
$$

where $L_{2}$ and $L_{3}$ are conditional likelihood functions of Eq. (2) and (3), respectively; $f\left(\eta_{2}, \eta_{3}\right)$ is the joint estimation of the unobserved heterogeneity components. The joint distribution of the unobserved effect $f\left(\eta_{2}, \eta_{3}\right)$ is assumed to be a two-dimensional normal distribution $[37,44]^{2}$ and this can be characterized as follows:

$$
\left(\begin{array}{l}
\eta_{3} \\
\eta_{2}
\end{array}\right) \approx N\left(\left[\begin{array}{l}
0 \\
0
\end{array}\right],\left[\begin{array}{c}
\sigma_{3}^{2} \\
\rho_{23} \sigma_{3} \sigma_{2}, \sigma_{2}^{2}
\end{array}\right]\right) .
$$

The full model in Eq. (5) is jointly estimated through the CMP framework, which uses the Geweke, Hajivassiliou, and Keane (GHK) algorithm to consistently estimate the likelihood function in Eq. (4) [44]. As previously stated, the primary objective of estimating Eqs. (2) and

\footnotetext{
${ }^{2}$ For further information regarding CMP equations, particularly Eq. 4 and 5 , kindly refer to Roodman [44].
} 
(3) together is to resolve the inherent bias in self-selection. Maitra [36] pointed out that the purpose of a joint estimation is to investigate the probability of a non-zero covariance between the error terms of equations (2) and (3), thus $\operatorname{cov}\left(\eta_{2}, \eta_{3}\right) \neq 0$. However, while the heterogeneity terms are conditioned, Eqs. (2) and (3) are independent. Therefore, the probability function in Eq. (4) can be calculated by multiplying the functions of Eq. (2) and (3) in terms of the individual conditional probability (Chamberlain et al. 1975). As the issue of suitable variables to serve as instruments to an endogenous variable (Eq. 2) has always been a challenge, the estimation of the Eqs. (2) and (3) jointly enables the estimation of the resulting variables to be extracted, as long as the two equations define them. Identification is thus made possible by the recursive existence of the CMP layout, where the outcome variable is affected by CLDI [37], Baum, 2016).

\section{Results and discussion}

Summary statistics of household socioeconomic and institutional variables

The summary statistics of the variables used in the model are presented in Table 2. The results show that the majority $(84 \%)$ of the household heads were male, while the remaining $16 \%$ were female. In addition, most (94\%) of the household heads were married. Meanwhile, the average age of a household head in northern Ghana was found to be about 48 years.

Table 2 indicates that about $89 \%$ of farmers are primarily engaged in agriculture. This was expected in agrarian economies like Ghana, where agriculture is the primary source of income for the majority of households. Irrigation was practiced by a small percentage of households (12\%). The average farm size was about four acres, with each household's farm size differing by four acres. This demonstrates that the majority of households in the study area are smallholder farmers. The majority of the households owned the land on which they farmed. A smaller proportion, approximately $13 \%$, of households rented the farmland on which they cultivate. These few households may be those that irrigate their farmlands during the dry season. As a result, households that want to irrigate but lack farmland near water sources may resort to renting land for cultivation during the dry season. In addition, the study took into account a wide range of institutional variables that have been proposed to influence crop-livestock diversification and/or food security. These include credit access, extension services, farmer groups, and offfarm employment. According to the findings, approximately $18.9 \%$ of the households had received agricultural credit in inputs or cash. In addition, approximately $60.8 \%$ of households had access to agricultural extension services, and $35.2 \%$ of households were members of community farmer groups. Finally, approximately $33 \%$ of households worked off-farm in occupations such as petty trading, carpentry, masonry, among others.

\section{Household food security situation in northern Ghana}

The result of the food security situation in northern Ghana is indicated by the household dietary diversity score (HDDS), which considers both the quality and quantity of food consumed. Figure 2 shows the distribution of household diversity scores. From the figure, most households had a HDDS above the average, as it is skewed to the right. It cannot be concluded that the majority of the households in northern Ghana are food secured since it might depend on the time of the season the data was collected and also the fact that the data on their dietary diversity was collected over the 7 days and not within the past $24 \mathrm{~h}$. However, the majority of the households in northern Ghana could be said to have a relatively higher dietary diversity score.

The average household dietary diversity was found to be 8.25 , which implies that on average, a household in northern Ghana consumes about 8 different food groups in a week. The standard deviation was also found to be about 1.89, suggesting that, given an average household dietary diversity score of 8.25 in northern Ghana, each household dietary score varies from the next by about 2 food groups. This suggests a somehow homogenous consumption in terms of diversity in the area.

\section{Crop-livestock diversification in northern Ghana}

The results of the Margalef index, which shows the extent of crop-livestock diversification in northern Ghana are reported in Table 3. Results in Table 3 show that no farm household in northern Ghana cultivate a single crop or rear a single kind of livestock or both, since the minimum level of diversification for all categories was greater than zero. This implies that all households in northern Ghana engage in some level of integrated crop-livestock diversification.

The Margalef index shows the average crop-livestock diversification in northern Ghana was about 1.71 with a minimum and maximum of 0.311 and 12.322 , respectively. The results show that much of the diversity came from the crops than livestock, with a Margalef index of 1.801 and 0.528 , respectively. Mekuria and Mekonnen [39] found the Margalef index for livestock to be tremendously higher $(0.86)$ than crops at 0.28 in the central highlands of Ethiopia. The same story could not be told of this study. However, this result was expected because most of the households in northern Ghana engage in crop farming than livestock rearing. Hence, even though there is zero specialization in livestock in northern 


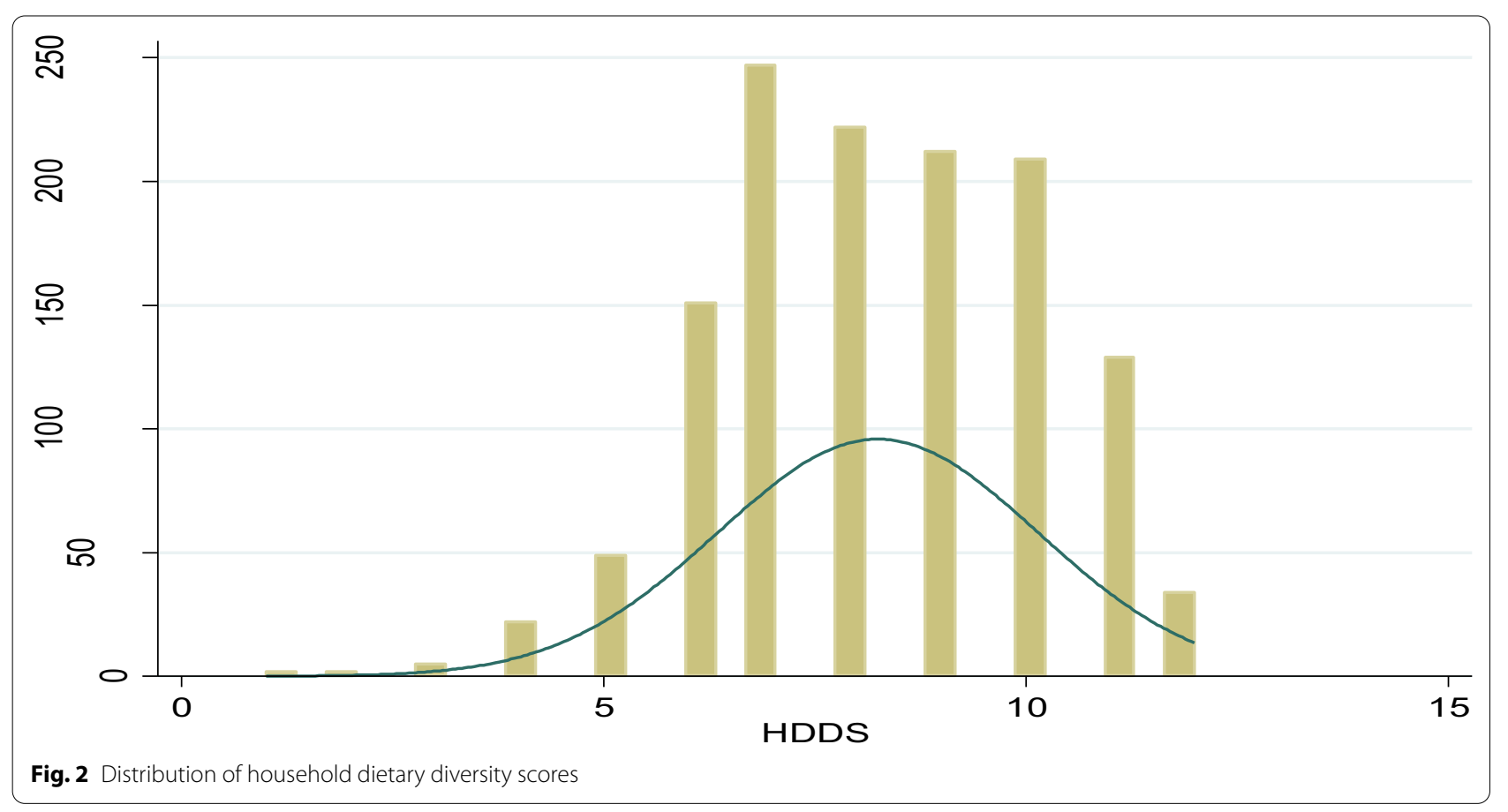

Table 3 Level of crop-livestock diversification in northern

\begin{tabular}{lllll}
\hline Diversification category & Mean & $\begin{array}{l}\text { Standard } \\
\text { deviation }\end{array}$ & Minimum & Maximum \\
\hline Crop diversity index & 1.801 & 1.55 & 0.271 & 9.865 \\
Livestock diversity index & 0.528 & 0.383 & 0.193 & 2.164 \\
$\begin{array}{l}\text { Crop-livestock diversity } \\
\text { index }\end{array}$ & 1.71 & 0.761 & 0.311 & 12.332 \\
\hline
\end{tabular}

Ghana, there is a low level of diversity (suggesting some degree of specialization) in the area.

\section{Determinants of crop-livestock diversification in northern Ghana}

The results of the CMP for the linear regression and the Tobit models are presented in Table 4. The first part of the regression is an estimate, which shows the factors influencing crop-livestock diversification, while the second is the Tobit model, which shows the effect of crop-livestock diversification on household food security. ${ }^{3}$ The $R$-squared for the linear regression was 0.435 , which shows that the model explains about $44 \%$ of the variations in crop-livestock diversification. The crosssectional correlation of the error terms of the equations (indicated by rho12) was also important. The estimated

\footnotetext{
3 The study ignores the regression analysis of both crop-diversification and livestock from the CMP model and concentrates on the crop-livestock diversification. This is because the main focus of the study is crop-livestock diversification.
}

rho demonstrates the primary indicator of endogeneity arising from the tendency of self-selection. Therefore, a significant rho coefficient indicates self-selection bias. A significant positive rho value suggests that certain non-observed variables positively impact both the endogenous and outcome variables. The opposite refers to a negative and significant value of rho. Therefore, the essential values of rho in the analysis justify the use of CMP; we therefore discussed more about determinants of crop-livestock diversification here, and its impact on food security in in the next section.

The empirical estimates of the determinants of croplivestock diversification are shown by the OLS model in Table 4. The results showed that household-specific, socioeconomic, and institutional factors influence integrated crop-livestock diversification in northern Ghana. Regarding household demographic factors, the results indicated that male-headed households had a higher probability of diversification than female-headed households. The difference in the crop-livestock diversity index between the male and female-headed households was about 0.272 . This suggests that male-headed households in northern Ghana had an extra Margelef index of 0.272 above female-headed households. This finding is consistent with Asante et al. [8], who found the gender of the household head to positively influence crop diversification in Ghana. This could be associated with the fact that most males can engage in rigorous and multiple farm enterprises than females. For livestock rearing, 
Table 4 Determinants of crop-livestock diversification and its impact on food security

\begin{tabular}{|c|c|c|c|}
\hline \multirow[t]{2}{*}{ Variable } & \multirow{2}{*}{$\begin{array}{l}\text { OLS model } \\
\text { Coefficient }\end{array}$} & \multicolumn{2}{|l|}{ Tobit model } \\
\hline & & Coefficients & Marginal effects \\
\hline \multicolumn{4}{|l|}{ Household-specific } \\
\hline Sex of household head & $0.272(0.057)^{* * *}$ & $0.389(0.267)$ & $0.272(0.057)$ \\
\hline Marital status of household head & $0.074(0.098)$ & & \\
\hline Age of household head & $-0.003(0.001)^{* *}$ & $-0.015(0.004)^{* * *}$ & $-0.003(0.001)^{* *}$ \\
\hline \multicolumn{4}{|l|}{ Socioeconomic } \\
\hline Occupation of household head & $0.359(0.250)$ & $-0.511(0.704)$ & $-0.359(250)$ \\
\hline Irrigation & $0.017(0.154)$ & & \\
\hline Farm size & $0.008(0.003)^{* *}$ & $0.206(0.037)^{* *}$ & $0.008(0.003)$ \\
\hline land ownership & $0.021(0.007)^{* *}$ & $0.357(0.415)$ & $0.021(0.007)$ \\
\hline \multicolumn{4}{|l|}{ Institutional factors } \\
\hline Credit access & $0.159(0.081)^{*}$ & $0.276(0.211)$ & $0.057(0.081)$ \\
\hline Extension service & $0.094(0.044)^{* *}$ & $0.345(0.126)^{* *}$ & $0.094(0.044)^{* *}$ \\
\hline Farmer groups & $0.065(0.046)$ & $0.025(0.121)$ & $0.065(0.046)$ \\
\hline Off-farm employment & $0.095(0.044)^{* *}$ & $0.587(0.021)^{* * *}$ & $0.095(0.046)^{* *}$ \\
\hline Crop diversity index & & $0.168(0.070)^{* *}$ & \\
\hline Livestock diversity index & & $0.069(0.182)$ & \\
\hline Crop-livestock diversity index & & $1.162(0.514)^{* *}$ & \\
\hline Constant & $1.933(0.538)^{* * *}$ & $8.380(1.552)^{* * *}$ & \\
\hline sig_1 & & $0.291(0.019)^{* * *}$ & \\
\hline Sig_2 & & $0.649(0.072)^{* * *}$ & \\
\hline rho_12 & & $0.371(0.198)^{* *}$ & \\
\hline R-squared $=0.435$ & & & \\
\hline
\end{tabular}

***, ** and * denote significant levels at 1,5 and 10 percent, respectively

it is a cultural norm for the males to rear livestock such as cattle in northern Ghana than females. As a result, the male-headed household focuses on other multiple crop-livestock enterprises as a form of mitigation against production risk. The age of the household head was also found to have a negative effect on crop-livestock diversification. The negative results of age to crop-livestock diversification could be because when household's heads grow older, they become less capable to multi-task than the energetic young household heads, hence, the negative effect is estimated. Asante et al. [8] found that the age of the household head has a positive effect on crop-livestock diversification with an insignificant but negative effect on livestock diversification in Ghana.

Also, two socioeconomic factors were identified to influence crop-livestock diversification namely; farm size and land ownership. An increase in the acreage of the farm size of a household could result in about 0.008 units of integrated crop-livestock diversification. This is consistent with that of Mekuria and Mekonnen [39], who found that farm size positively influences crop-livestock diversification in the central highlands of Ethiopia. This was expected because the larger the farm size, the higher the probability that the household will farm different kinds of crops and raise livestock as compared to those with small farm sizes. We also investigated the effect of land ownership on crop-livestock diversification. This was necessary because land ownership offers an incentive for the growth and expansion of one's farm enterprise than a rented one. This again coincides with the results of Asante et al. [8], who also found households who own lands to have a positive effect on integrated crop-livestock diversification in Ghana.

Moreover, households who accessed ${ }^{4}$ supply-side policy instruments such as agricultural credit facility and agricultural extension services diversify more than those who did not. Access to credit is crucial for farmers to finance the establishment and maintenance of crop farms and animals in order to integrate them for increased food security. To diversify agricultural production into livestock, or vice versa, a farmer requires financial liquidity to purchase additional lands for both crops and animals and other inputs (e.g. labor) and equipment for crop cultivation. Thus, the availability of financing to farmers in the

\footnotetext{
${ }^{4}$ The mean VIF (variance inflation factor) was found to be 1.53 which showed that, there was no multicollinearity between the selected independent variables. Also, the probability value of the Breusch-Pagan test was 0.125 which showed that there were no issues of heteroscedasticity
} 
form of cash or input supply could hasten the process of crop-livestock diversification. Regarding access to extension, farming households who had gained knowledge and technical skills through extension services are about 9.4\% more likely to intensify their crop-livestock diversification processes than their counterparts who received no extension services. Asante et al. [8] and Mekuria and Mekonnen [39] also found access to agricultural extension services to have a positive and significant effect on crop diversification and integrated crop-livestock diversification in Ghana and Ethiopia, respectively. Further studies by Asante et al. [7] also found that agricultural extension services influence households' probability to diversify and result in a significant reduction of inefficiencies within the integrated crop-livestock diversification system. The reason for this is that these households are trained and educated on productive farming systems such as the integrated crop-livestock diversification system, where the residues from crops are used as feed for livestock, while droppings or dung from livestock are used as manure for crops. Finally, off-farm employment, which constitutes all forms of business and employment opportunities outside the farm enterprise, significantly influenced crop-livestock diversification. This suggests that when farmers engage in other employment opportunities, they can reinvest the income generated from such enterprises in their crop farm operations or diversify into livestock as a mitigation strategy against the global threat of climate change. This is close to the results of Asante et al. [7], which showed that the share of household nonfarm incomes greatly decreased inefficiencies in Ghana's integrated crop-livestock systems. Though Mekuria and Mekonnen [39] found that off-farm income negatively influenced crop-livestock diversification in Ethiopia, the marginal effect was negligible in explaining the decrease in crop-livestock diversification due to an increase in off-farm income. Hence, the results of this study suggest some complementary roles of off-farm income in croplivestock diversification.

\section{Impact of crop-livestock diversification on food security in northern Ghana}

The last two columns of Table 4 are the results of the Tobit model, which among other variables, unravels the effect of crop-livestock diversification on household food security. We included separate crop and livestock diversification indices and the integrated crop-livestock diversification index to envisage the effects of both separate systems and the synergy when it is integrated. The study provides some interesting results regarding the effects of some household-specific, socioeconomic, and institutional variables aside from the variable of interest, on food security.
The age of the household head was negatively related to the HDDS. This suggests that younger households have better dietary diversity as compared to elderly household heads. The negative effect of age on dietary diversity could be associated with taste and physical manpower to work. The reason is that the youth have the aptitude for a varied group of food categories than the elderly. Also, the younger household heads can work on their farms and perhaps outside their farms because they are more energetic than the elderly. Hence, the negative direction of influence is not a surprise. However, the magnitude of the marginal effect was small since an additional increase in the age of a household head only decreases their dietary diversity by 0.003 scores, ceteris paribus.

With the socioeconomic factors considered, only the farm size owned by the household was significant in explaining the household dietary diversity score. The results showed that when the farm size of a household increases by 1 acre, their dietary diversity will increase by 0.206 , holding all other factors constant. Aidoo et al. [3] also found that farm size has a positive and significant effect on food security in the Sekyere Afram Plains of Ghana. This was expected because households with large farm sizes can cultivate different varieties of crops and rear livestock. Households with larger agricultural landholdings can generate income by leasing out a proportion of it, which will help improve their food security situation. Also, food production is increased in larger farm sizes as compared to smaller farm sizes.

Two variables: access to agricultural extension services and off-farm jobs positively influenced HDDS in northern Ghana. The positive effect of agricultural extension service on food security is consistent with Chege et al. [11], who also found extension services to positively and significantly affect food security in Kenya. The extension service is also expected to educate farmers on the need to cultivate multiple crop varieties as one of the adaptation measures to counter the adverse effects of climate change. Kikpurgat and Tuigong [32], using a qualitative research approach, also recommended the need to invest in agricultural extension delivery if food security must be achieved in Kenya. Moreover, Danso-Abbeam et al. [13] found that agricultural extension services play a critical role in enhancing farm productivity and household income in northern Ghana, which could help improve household consumption and food security. The positive effect of off-farm employment on household food security was also expected because these are expected to increase household income, improving their consumption pattern. Income could also be used to cultivate a diverse range of crops or livestock, which results in improved food security. Aidoo et al. [3] found that off-farm employment positively and significantly affects 
household food security in the Sekyere-Afram Plains of Ghana. This result is also consistent with a recent study by Dzanku [20], who found that off-farm employment was positively related to food security with a high propensity to reduce food insecurity in fifteen regions of Sub-Saharan Africa, including Ghana. Murendo et al. [41] also found similar results in Zimbabwe, where offfarm income positively affected household food security.

Turning to the variable of interest, the crop-livestock diversification index included the three separate diversity indices: crop-diversification, livestock-diversification, and integrated crop-livestock diversification. The results show that the crop diversity index had a positive and statistically significant effect on food security, but the effect of the livestock diversification index was not significant. However, the integrated crop-livestock diversity index was found to positively and significantly affect food security at a $5 \%$ significance level. This implies that the livestock diversity for most of the households cannot ensure food security compared with that of the crops. It is also important to note that, while most households in northern Ghana cultivate a varied number of crop types, most of the livestock are not so much varied, which could be the reason for the insignificant effect of the livestock diversity index. However, this does not imply that they do not generate enough income from livestock because the index measures the spread and not the volume. Murendo et al. [41] found that these two diversity indices strongly positively affect household dietary diversity and food consumption in Zimbabwe. Murendo et al. [42] failed to show the combined effect of the two in their study. This study did not show a significant effect of the livestock diversity index on household food security but agree with their findings on the crop diversification index. Interestingly, we find that the integrated crop-livestock diversity significantly explained household food security status in northern Ghana. The positive effect of the integrated crop-livestock diversification index was expected due to the benefits emanating from the interaction of the two systems.

\section{Conclusion and recommendations}

This study's main objective was to examine the impact of crop-livestock diversification on household food security in northern Ghana. Cross-sectional data collected from 1284 households by the International Food Policy Research Institute (IFPRI) under the Ghana Africa Research in Sustainable Intensification for the Next Generation (Africa RISING) 2015 baseline survey was used for the study. The Margalef index was first used to compute the crop-livestock diversification index, while the household dietary diversity score was used to measure food security. Employing both linear regression and double-censored Tobit models within the framework of CMP, the study identified the factors influencing croplivestock diversification and the effect of crop-livestock diversification on household food security. The results showed that household-specific factors, socioeconomic factors, as well as institutional factors, influence croplivestock diversification and food security in northern Ghana. Moreover, crop-livestock diversification was found to have a positive and statistically significant effect on household food security. Thus, the study recommends that crop-livestock diversification could help in Ghana's pursuit of the zero-hunger agenda (i.e., Sustainable Development Goal 2 (SDG2)) since it improves food security without adversely affecting biodiversity and ecosystem health. This could be achieved by incorporating it in the current planting and rearing for food and jobs programme.

\section{Acknowledgements}

We thank the International Food Policy Research Institute (IFPRI) for making the data available for this study.

\section{Authors' contributions}

GDA conceptualized the title, perform the analysis and discuss the results; GD wrote the methodology, DSE wrote the introduction and the conclusions, AAO worked on the reviewers' comments, reviewed the entire paper and make significant contributions. ES and JAA reviewed the work and offered significant contributions. All authors have read and approved the final manuscript.

\section{Funding}

The authors did not receive any funding for the study.

\section{Availability of data and materials}

The datasets during and/or analyzed during the current study are available from the corresponding author on reasonable request.

\section{Declarations}

Ethics approval and consent to participate

Consent to participate in the survey was obtained from each respondent, and confidentiality was assured.

\section{Consent for publication}

Not applicable.

\section{Competing interests}

The authors declare that they have no competing interests.

\section{Author details}

${ }^{1}$ Department of Agricultural Administration and Marketing, University for Development Studies, Tamale, Ghana. ${ }^{2}$ Department of Agricultural Economics, University of the Free State, Bloemfontein, South Africa. ${ }^{3}$ Science Department, St. John Bosco's College of Education, Navrongo, Ghana. ${ }^{4}$ Department of Economics, University for Development Studies, Tamale, Ghana.

Received: 22 December 2020 Accepted: 17 June 2021

Published online: 04 September 2021 


\section{References}

1. Afulani P, Herman D, Coleman-Jensen A, Harrison GG. Food insecurity and health outcomes among older adults: the role of cost-related medication underuse. J Nut Gerontol Geriatr. 2015;34(3):319-42.

2. Agyeman BAS, Asuming-Brempong S, Onumah EE. Determinants of income diversification of farm households in the western region of Ghana. Q J Int Agric. 2014:53(1):55-72.

3. Aidoo R, Mensah JO, Tuffour T. Determinants of household food security in the Sekyere-Afram plains district of Ghana. Eur Sci J. 2013;9(21). https:// doi.org/10.19044/esj.2013.v9n21p\%25p.

4. Aliaga MA, Chaves-Dos-Santos SM. Food and nutrition security public initiatives from a human and socioeconomic development perspective: mapping experiences within the 1996 World Food Summit signatories. Soc Sci Med. 2014:104:74-9.

5. Ansah IGK, Gardebroek C, Ihle R. Resilience and household food security: a review of concepts, methodological approaches and empirical evidence. Food Sec. 2018;11:1187-203.

6. Asfaw S, Lipper L. Adaptation to climate change and its impact on food security: evidence from Niger. In: Paper presented at the 29th International Conference of Agricultural Economists, August 8-14, Milan, Italy; 2015.

7. Asante BO, Villano RA, Battese GE. Evaluating complementary synergies in integrated crop-livestock systems in Ghana. Int J Soc Econ. 2019. https:// doi.org/10.1108/IJSE-04-2019-0274.

8. Asante BO, Villano RA, Patrick IW, Battese GE. Determinants of farm diversification in integrated crop-livestock farming systems in Ghana. Renew Agric Food Syst. 2018;33(2):131-49.

9. Caccavale OM, Giuffrida V. The proteus composite index: towards a better metric for global food security. World Dev. 2020;126:104709.

10. Cafiero C, Viviani S, Nord M. Food security measurement in a global context. The food insecurity experience scale. Measurement. 2018;116:146-52

11. Chege JM, Lemba JK, Semenye PP. Influence of agricultural extension on household food security status among the smallholder farmers. Adv Res. 2018;1-9

12. Dagunga G, Sedem Ehiakpor D, Kwabena Parry I, Danso-Abbeam G. Determinants of income diversification among maize farm households in the garu-tempane district, Ghana. Rev Agric Appl Econ. 2018;21:55-63.

13. Danso-Abbeam G, Ehiakpor DS, Aidoo R. Agricultural extension and its effects on-farm productivity and income: insight from Northern Ghana. Agric Food Sec. 2018;7(1):1-10.

14. Danso-Abbeam G, Baiyegunhi LJS, Laing MD, Shimelis H. Understanding the determinants of food security among rural farming households in Rwanda. Ecol Food Nutr. 2021. https://doi.org/10.1080/03670244. 2021.1913585

15. Darfour B, Rosentrater KA. Agriculture and food security in Ghana. In: 2016 ASABE Annual International Meeting 2016 (p. 1). American Society of Agricultural and Biological Engineers. Doi:https://doi.org/10. 13031/aim.20162460507

16. Devereux S. Distinguishing between chronic and transitory food insecurity in emergency needs assessments SENAC. Rome: WFP; 2006

17. Dittoh S. Green revolution or revolution? The case of independent African countries. Africa Development/Afrique et Développement ; 1981. pp. 48-62.

18. Drysdale RE, Moshabela M, Bob U. Adapting the coping strategies index to measure food insecurity in the rural districts of iLembe, South Africa. Food Cult Soc. 2019;22(1):95-110.

19. Dubbert C. Participation in contract farming and farm performance: Insights from cashew farmers in Ghana. Agric Econ. 2019;50:749-63.

20. Dzanku FM. Food security in rural sub-Saharan Africa: Exploring the nexus between gender, geography and off-farm employment. World Dev. 2019;113:26-43

21. FAO Policy Brief: Food Security. (2006) http://www.fao.org/forestry/ 13128-0e6f36f27e0091055bec28ebe830f46b3.pdf.

22. FAO. The state of food insecurity in the world: addressing food insecurity in protracted crises. Rome: FAO; 2010.

23. FAO. Guidelines for measuring household and individual dietary diversity, Rome; 2011.

24. FAO. Livelihood diversification and vulnerability to poverty in rural Malawi. SSRN. 2015. https://doi.org/10.22004/ag.econ.288974.
25. FAO, IFAD, UNICEF, WFP, WHO. The state of food security and nutrition in the world 2017. Building Resilience for Peace and Food Security. FAO, Rome; 2018

26. Haysom G, Tawodzera G. "Measurement drives diagnosis and response": gaps in transferring food security assessment to the urban scale. Food Policy. 2018;74:117-25.

27. Iiyama M, Kariuki P, Kristjanson P, Kaitibie S, Maitima J. Livelihood diversification strategies, incomes and soil management strategies: a case study from Kerio Valley, Kenya. J Int Dev. 2008;20(3): 380-97.

28. INDDEX Project, Data4Diets: Building Blocks for Diet-related Food Security Analysis. Tufts University, Boston; 2018. https://inddex.nutri tion.tufts.edu/data4diets. Accessed 2 May 2020.

29. Jackson BD, Walker N, Heidkamp R. Metrics for identifying food security status and the population with potential to benefit from nutrition interventions in the Lives Saved Tool (List). J Nutr. 2017; 147(11):2147S-55S

30. Jones AD, Ngure FM, Pelto G, Young SL. What are we assessing when we measure food security? A compendium and review of current metrics. Am Soc Nutr. 2013;4:481-505.

31. Klennert K. Achieving Food and Nutrition Security. Feldafingen: InWEnt; 2009.

32. Lawlis T, Islam W, Upton P. Achieving the four dimensions of food security resettled refugees in Australia: a systematic review. Nutr Diet. 2018;75:182-92.

33. Leroy JL, Ruel M, Frongillo EA, Harris J, Ballard TJ. Measuring the food access dimension of food security: a critical review and mapping of indicators. Food Nutr Bull. 2015;36(2):167-95.

34. Liniger H, Mekdaschi SR, Hauert C, Gurtner M. Sustainable land management in practice: guidelines and best practices for Sub-Saharan Africa: field application. Rome: FAO; 2011.

35. Makate C, Wang R, Makate C, Mango N. Crop diversification and livelihoods of smallholder farmers in Zimbabwe: adaptive management for environmental change. Springerplus. 2016:5:1135.

36. Maitra P. Parental bargaining, health inputs and child mortality in India. J Health Econ. 2004;23:259-91.

37. Martey E, Etwire PM, Kuwornu KM. Economic Impacts of smallholder farmers'adoption of drought-tolerant maize varieties. Land Use Policy. 2020. https://doi.org/10.1016/j.landusepol.2020.104524.

38. Maxwell D, Coates J. Reaching for the stars? Identifying universal measures of food insecurity. Paper presented at the FAO International Scientific Symposium on Food and Nutrition Security Information, Rome, Italy, 17-19 January, 2012; 2019.

39. Mekuria W, Mekonnen K. Determinants of crop-livestock diversification in the mixed farming systems: evidence from central highlands of Ethiopia. Agric Food Secur. 2018;7(1):1-15.

40. Ministry of Food and Agriculture [MoFA]. Food and Agriculture Sector Development Policy II (FASDEP II). Accra, Ghana; 2007. https://www.grain org/media/W1 siZilsljlwMTMvMDIvMjgvMTRfMjhfMTZfNzUxXOZBUORFUF 9JSV9GSU5BTC5wZGYiXV0. Accessed 18 Aug 2020.

41. Murendo C, Gwara S, Mazvimavi K, Arensen JS. Linking crop and livestock diversification to household nutrition: evidence from Guruve and Mt Darwin districts Zimbabwe. World Dev Perspect. 2019;14:100104.

42. Nkegbe PK, Abu BM, Issahaku H. Food security in the savannah accelerated development authority zone of Ghana: an ordered probit with household hunger scale approach. Agric Food Secur. 2017;6(1):35.

43. Pinstrup-Andersen P. Food security: Definition and measurement. Food Secur. 2009:1:5-7.

44. Roodman D. Fitting fully observed recursive mixed-process models with CMP. STATA J. 2011;11:159-206.

45. Santermo FG. On the composite indicators for food security: decision matters! Food Rev Int. 2015;31:63-73.

46. Smith $L C$, El Obeid $A E$, Jensen $H H$. The geography and causes of food insecurity in developing countries. Agric Econ. 2000;22(2):199-215.

47. Sinyolo S. Technology adoption and household food security among rural households in South Africa: the role of improved maize varieties. Technol Soc. 2020. https://doi.org/10.1016/j.techsoc.2019.101214.

48. Statista Ghana: Distribution of employment by economic sector from 2009 to 2013. (2019) https://www.statista.com/statistics/447530/emplo yment-by-economic-sector-in-ghana/. Accessed 25 Apr 2020

49. Stark F, González-García E, Navegantes L, Miranda T, Poccard-Chapuis $\mathrm{R}$, Archimède $\mathrm{H}$, Moulin $\mathrm{CH}$. Crop-livestock integration determines the 
agroecological performance of mixed farming systems in Latino-Caribbean farms. Agron Sustain Dev. 2018;38(1):1-11.

50. Sumner J. Imagining the possibilities-food, leisure and the future of eating. Ann Leisure Res. 2020;23(4):562-5.

51. Tuholske C, Andam KS, Blekking J, Evans T, Caylor K. Measurement and determinants of urban food security: evidence from Accra, Ghana. International Food Policy and Research Institute (IFPRI), Strategy Support Program, Working Paper 50; 2018.

52. United Nations (UN) (2015). Transforming Our World: The 2030 Agenda for Sustainable Development. United Nations, New York. (2015) https:// sustainabledevelopment.un.org/post2015/transformingourworld/publi cation. Accessed 15 Aug 2020.

53. United States Agency for International Development [USAID] The Global Food Security Strategy (GFSS): Ghana Country Plan, (2018) https://www. usaid.gov/sites/default/files/documents/1867/Ghana_Country_Plan_ Public Version_WS_Edits.pdf Accessed 19 Sept 2020.
54. Waha K, Van Wijk MT, Fritz S, See L, Thornton PK, Wichern J, Herrero M. Agricultural diversification as an important strategy for achieving food security in Africa. Global Change Biol. 2018;24(8):3390-400.

55. WFP. Food Security and Nutrition Monitoring Systems, Ghana. (2020) https://reliefweb.int/sites/reliefweb.int/files/resources/WFP-0000119574. pdf. Accessed 21 May 2021.

56. World Bank. Poverty and hunger: issues and options for food security in developing countries. Washington DC: A World Bank Policy Study; 1986. https://documents.worldbank.org/en/publication/documents-reports/ documentdetail/166331467990005748/poverty-and-hunger-issues-andoptions-for-food-security-in-developingcountries Accessed 17 Sept 2020.

\section{Publisher's Note}

Springer Nature remains neutral with regard to jurisdictional claims in published maps and institutional affiliations.
Ready to submit your research? Choose BMC and benefit from:

- fast, convenient online submission

- thorough peer review by experienced researchers in your field

- rapid publication on acceptance

- support for research data, including large and complex data types

- gold Open Access which fosters wider collaboration and increased citations

- maximum visibility for your research: over $100 \mathrm{M}$ website views per year

At BMC, research is always in progress.

Learn more biomedcentral.com/submissions 